\title{
Risk factors of obesity among Brazilian adolescents: a case-control study
}

\author{
Marilda B Neutzling ${ }^{1, *}$, José Augusto AC Taddei ${ }^{2}$ and Denise P Gigante ${ }^{1}$ \\ 'Departamento de Nutrição, Faculdade de Nutrição, Universidade Federal de Pelotas, Campus Universitário, \\ CP 354, Pelotas, RS, CEP $96010-900$, Brazil: ${ }^{2}$ Departamento de Pediatria, Escola Paulista de Medicina, \\ Universidade Federal do Estado de São Paulo, Rua Loefgreen 1647, Vila Clementino, São Paulo, SP, \\ CEP 04040-032, Brazil
}

Submitted 6 January 2003: Accepted 19 May 2003

\begin{abstract}
Objective: To study risk factors associated with overweight and obesity among adolescents enrolled in private high schools in the city of Pelotas, southern Brazil. Method: This was a case-control study. The subjects were 264 overweight (body mass index (BMI) $\geq 85$ th percentile of the National Center for Health Statistics (NCHS) reference population) and 264 non-overweight (BMI $>5$ th and $<85$ th NCHS percentiles) adolescents identified by means of an anthropometric survey which included 1608 students. The adolescents were weighed, measured and interviewed about food habits and physical activity at school. Parents provided their own weights and heights when contacted by telephone, and parental BMI was calculated.

Results: Hierarchical multiple conditional logistic regression showed that overweight and obesity were positively associated with mother's (odds ratio (OR) 2.86, 95\% confidence interval $(\mathrm{Cl})$ 1.43-5.74) and father's (OR 2.43, 95\% $\mathrm{Cl} 1.37-4.30) \mathrm{BMI}$ $\geq 30 \mathrm{~kg} \mathrm{~m}^{-2}$, being overweight before 10 years of age (OR 2.26, 95\% Cl 1.30-3.90) and the habit of dieting (OR 3.53, 95\% Cl 1.76-7.22). Having more than three meals per day was found to be a protective factor against overweight and obesity (OR 0.54, 95\% Cl 0.29-1.00).

Conclusion: The present study showed that a family history of obesity, overweight during childhood and the habit of dieting for weight-loss purposes are factors associated with obesity during adolescence. The habit of having more than three daily meals turned out to be a protective factor against overweight. These results suggest the necessity for early intervention at the family and general community levels aimed at the prevention of obesity through actions directed towards the modification of established behaviours.
\end{abstract}

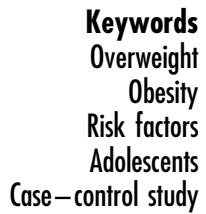

Longitudinal studies have shown that obesity in childhood and adolescence, particularly during the second decade of life, is a strong predictor of adult obesity, especially for extremely obese children with obese parents ${ }^{1-4}$. At the same time, there is increasing evidence that the development of overweight and obesity in adolescence has deleterious social, economic ${ }^{5}$ and health consequences ${ }^{6,7}$. The psychosocial discrimination of obese adolescents may lead them to social isolation and affect their psychological development ${ }^{8}$.

Obesity during childhood and adolescence is increasing dramatically in the Western world. In the USA, the prevalence of obesity among individuals aged between 6 and 17 years (body mass index $(\mathrm{BMI}) \geq 95$ th percentile of the National Center for Health Statistics (NCHS) reference population) has almost tripled in 30 years, from 4\% in 1963 to $11 \%$ in 1994 . In the same year, an additional 14\% had a BMI between the 85 th and 95 th percentiles 9 . Although there are both genetic and environmental causes of obesity, closely associated with changes in environmental factors ${ }^{8}$.

Risk factors may vary amongst and within societies exposed to different environmental influences ${ }^{10}$. Demographic, epidemiological and nutritional transition processes have different characteristics in different countries ${ }^{11}$. In Latin America, the social, economic and demographic transformations that have taken place during the last decades coincided with modifications in the region's epidemiological profile and dietary ${ }^{12}$ and physical activity patterns. Analysis of data from the Brazilian National Survey showed associations between overweight, income, urbanisation and region of residence, indicating that the environment represents an important risk factor for overweight and obesity amongst Brazilian adolescents ${ }^{13}$.

Thus, nowadays, obesity during adolescence is an important public health problem in developing as well as the increase in obesity prevalence is likely to be more 
in developed countries. In spite of the problem's magnitude, however, little is known about the factors that contribute to the world-wide obesity epidemic. It is urgent, therefore, to evaluate the factors that determine this process in every different region and in every different culture. The present study attempted to investigate the risk factors associated with overweight and obesity amongst adolescents, aged 15 to 19 years, enrolled in private high schools in the city of Pelotas, southern Brazil.

\section{Methodology}

The case-control study was performed in the city of Pelotas, in the state of Rio Grande do Sul, southern Brazil, from 2 August to 4 December 2000.

For case selection, from February to June 2000, a team of trained university students (School of Nutrition, Federal University of Pelotas) weighed and measured 1608 adolescents born between 01/01/1980 and 12/31/1985, which represented $96.6 \%$ of all students participating in physical education (PE) classes in all private high schools of the city of Pelotas. We selected private schools because the highest prevalence of obesity among Brazilian adolescents was found among the upper-income class living in southern Brazil ${ }^{13}$. Approximately 6\% (106) of the 1770 students enrolled did not participate in PE classes for medical reasons. Seven youngsters refused to submit to evaluation, and 49 were not located after at least three attempts.

Cases comprised the 264 (16.4\%) adolescents identified, amongst the 1608 examined, as presenting a BMI (defined as weight in $\mathrm{kg}$ divided by the square of height in $\mathrm{m}$ ) $\geq 85$ th percentile of the NCHS reference population. For each of these 264 cases we chose one control. Sample size allowed the detection of an odds ratio (OR) of 1.75 , given a prevalence of sedentarianism among controls of $30 \%$, a power of $80 \%$ and an alpha error of $5 \%$.

Controls were matched by gender and age, and selected from subjects presenting a BMI-for-age between the 5th and 85th NCHS percentiles. The choice of these cut-off points aimed to ensure that only adequately nourished adolescents were selected as controls. Of the 1608 adolescents initially evaluated, 43 (2.7\%) were below the 5th NCHS percentile and were therefore excluded from the process of control selection. After ordering all subjects by sex and date of birth, controls were selected by choosing the individual with a date of birth immediately after each case.

A standardised and pre-coded questionnaire was applied to both cases and controls. The following variables were considered: age; frequency and amount of physical activity; hours of sleep; hours of watching television (TV), playing video games and using a computer per day; dietary habits (frequency of fried foods, fast foods, sweets, soft drinks, fruit, vegetables and apparent meat fat); number of daily meals; sexual maturity (menarche for girls and axillary hair for boys) ${ }^{14}$; smoking (smoker/non-smoker); and dieting for weight-loss reasons (current diet). The adolescent's perception of his/her nutritional status before age 10 was also investigated. Socio-economic status was measured by ABIPEME (Associação Brasileira de Institutos de Mercado) - a variable obtained through information about home utensils and schooling level, and categorised as A, B, C, D and E from highest to lowest socio-economic status $^{15}$. Socio-economic status was not considered in the analysis because all adolescents were classified in the upper class categories.

In addition to the interview with the adolescent, parents or guardians were also contacted by telephone. At this time, data were collected concerning the adolescent (total breast-feeding duration, birth weight) and the biological parents (weight, height, schooling). Parents' nutritional status was evaluated by means of their BMI.

The adolescents were interviewed during their PE classes for approximately $40 \mathrm{~min}$. Fifteen adolescents (six cases and nine controls) who had left the school in the second semester of 2000 were interviewed at their homes.

Data were coded daily by the interviewers and revised by the study co-ordinator. The database was structured using Epi-Info 6.0 software (Centers for Disease Control and Prevention, Atlanta, GA, USA), with data being entered twice for the correction of possible entry mistakes. Analyses were performed using SPSS for Windows 8.0 (SPSS Inc., Chicago, IL, USA) and Stata (StataCorp, College Station, TX, USA) software.

Initially, univariate analysis was carried out on all information collected, calculating the proportions for the categorical variables. Next, bivariate analyses were performed, observing exposure prevalences for cases and controls, association tests (Pearson's chi-square test) and ORs with their respective 95\% confidence intervals (CIs). Finally, multivariate analysis was carried out, using a conditional logistic regression ${ }^{16}$ according to a hierarchical conceptual model ${ }^{17}$. Variables were included following the sequence proposed by the model. At each hierarchical level, variables associated with overweight and obesity with $P<0.20$ were maintained for their status as possible confounders ${ }^{18}$.

\section{Results}

A total of 508 adolescents (254 cases and 254 controls) were interviewed; there was a $3.9 \%$ loss in relation to the sample originally predicted. Ten pairs were lost (in one pair, case and control were not located; nine pairs were excluded because adolescents in the case or control group were not identified).

Table 1 describes the demographic and socio-economic characteristics of cases and controls. Over half the subjects were males and aged between 15 and 16 years. Subjects were concentrated in the higher socio-economic levels (A and $\mathrm{B}$ ); case and control distributions in relation to 
Table 1 Distribution of cases and controls according to gender, age and socio-economic characteristics: private high schools, Pelotas, southern Brazil, 2000

\begin{tabular}{|c|c|c|c|c|c|}
\hline \multirow[b]{2}{*}{ Variable } & \multicolumn{2}{|c|}{$\begin{array}{c}\text { Cases } \\
\text { (BMI } \geq 85 \text { th } \\
\text { percentile) }\end{array}$} & \multicolumn{2}{|c|}{$\begin{array}{l}\text { Controls } \\
\text { (BMI > 5th } \\
\text { and }<85 \text { th } \\
\text { percentile) }\end{array}$} & \multirow[b]{2}{*}{$P$-value } \\
\hline & $n$ & $\%$ & $n$ & $\%$ & \\
\hline \multicolumn{6}{|l|}{ Gender } \\
\hline Female & 104 & 40.9 & 104 & 40.9 & \\
\hline Male & 150 & 59.1 & 150 & 59.1 & 0.54 \\
\hline \multicolumn{6}{|c|}{ Age (years) } \\
\hline $15-16$ & 143 & 56.3 & 141 & 55.5 & \\
\hline $17-20$ & 111 & 43.7 & 113 & 44.5 & 0.46 \\
\hline \multicolumn{6}{|c|}{ Socio-economic status (ABIPEME)* } \\
\hline Class A & 189 & 74.7 & 195 & 76.8 & \\
\hline Class B & 64 & 25.3 & 59 & 23.2 & 0.59 \\
\hline \multicolumn{6}{|c|}{ Years of schooling - father (telephone interview) $\dagger$} \\
\hline$\leq 11$ & 86 & 36.1 & 82 & 34.9 & \\
\hline $12-15$ & 59 & 24.8 & 62 & 26.4 & \\
\hline$\geq 16$ & 93 & 39.1 & 91 & 38.9 & 0.92 \\
\hline \multicolumn{6}{|c|}{ Years of schooling - mother (telephone interview) $\ddagger$} \\
\hline$\leq 11$ & 78 & 32.0 & 79 & 31.9 & \\
\hline $12-15$ & 100 & 41.0 & 103 & 41.5 & \\
\hline$\geq 16$ & 66 & 27.0 & 66 & 26.6 & 0.99 \\
\hline
\end{tabular}

BMI - body mass index; ABIPEME - Associação Brasileira de Institutos de Mercado.

*Total of 507: schooling was not provided for one head of household.

†Total of 473: 35 did not have a father.

$\ddagger$ Total of 492: 16 did not have a mother. socio-economic level and parents' schooling were similar. The majority of youngsters were found to be sexually mature; all of them had axillary hair, and only one girl had not yet menstruated. Of the 254 overweight adolescents, $63(24.8 \%)$ had a BMI $\geq 95$ th percentile.

Table 2 shows risk factor distributions for cases and controls, crude ORs and their respective confidence intervals, as well as statistical significance tests for categorical variables.

Parental nutritional status was directly and significantly associated with overweight and obesity in adolescents. Youngsters whose parents' BMI was $\geq 30 \mathrm{~kg} \mathrm{~m}^{-2}$ were two times more likely to be overweight or obese than those whose parents were thinner. Birth weight was also found to be a risk factor in the crude analysis (OR 1.53). Having been breast-fed for 2 months or more (OR 0.67) seemed to have a protective effect against obesity.

Childhood overweight showed a direct relationship to overweight and obesity during adolescence. Youngsters who reported being overweight before age 10 were twoand-a-half times more likely to be overweight or obese during adolescence (OR 2.50). Cases did not differ from controls concerning physical activity. The habit of spending $4 \mathrm{~h}$ or more watching TV per day was more frequent amongst cases (OR 1.76).

Table 2 Odds ratio (OR) and respective 95\% confidence interval $(\mathrm{Cl})$ for characteristics related to obesity in adolescents aged 15 to 19 years enrolled in private high schools in the city of Pelotas, southern Brazil, 2000

\begin{tabular}{|c|c|c|c|c|c|c|c|c|}
\hline \multirow[b]{3}{*}{ Variable } & \multicolumn{3}{|c|}{ Cases } & \multicolumn{3}{|c|}{ Controls } & \multirow[b]{3}{*}{ Crude OR $(95 \% \mathrm{Cl})$} & \multirow[b]{3}{*}{$P$-value } \\
\hline & \multirow[b]{2}{*}{$n$} & \multicolumn{2}{|c|}{ Yes } & \multirow[b]{2}{*}{$n$} & \multicolumn{2}{|c|}{ Yes } & & \\
\hline & & $n$ & $\%$ & & $n$ & $\%$ & & \\
\hline \multicolumn{9}{|l|}{ Parental history } \\
\hline Father's BMI $\geq 30 \mathrm{~kg} \mathrm{~m}^{-2}$ & 228 & 64 & 28.1 & 230 & 31 & 13.5 & $2.51(1.52-4.15)$ & $<0.001$ \\
\hline Mother's BMI $\geq 30 \mathrm{~kg} \mathrm{~m}^{-2}$ & 239 & 41 & 17.2 & 247 & 19 & 7.7 & $2.48(1.35-4.61)$ & 0.001 \\
\hline \multicolumn{9}{|l|}{ Adolescent's history } \\
\hline Birth weight $\geq 3.8 \mathrm{~kg}$ & 250 & 72 & 28.8 & 254 & 53 & 20.9 & $1.53(1.00-2.36)$ & 0.04 \\
\hline Breast-fed $>2$ months & 252 & 175 & 69.4 & 251 & 194 & 77.3 & $0.67(0.44-1.01)$ & 0.05 \\
\hline Self-perception of overweight before age 10 & 254 & 95 & 37.4 & 254 & 49 & 19.3 & $2.50(1.64-3.81)$ & $<0.001$ \\
\hline Age at menarche $\leq 11$ years & 97 & 39 & 40.2 & 99 & 27 & 27.3 & $1.79(0.94-3.42)$ & 0.06 \\
\hline \multicolumn{9}{|l|}{ Physical activity (PA) } \\
\hline PA outside school & 254 & 160 & 63.0 & 254 & 174 & 68.5 & $0.78(0.53-1.15)$ & 0.19 \\
\hline$P A \geq 3$ times/week & 254 & 119 & 46.9 & 254 & 126 & 49.6 & $0.90(0.62-1.29)$ & 0.53 \\
\hline$P A \geq 30 \mathrm{~min} /$ day & 254 & 114 & 44.9 & 254 & 107 & 42.1 & $1.12(0.78-1.61)$ & 0.53 \\
\hline Sleep $>8 \mathrm{~h} /$ day & 254 & 57 & 22.4 & 254 & 70 & 27.6 & $0.76(0.50-1.16)$ & 0.18 \\
\hline $\begin{array}{l}\text { Watching TV, playing video games and } \\
\text { using a computer } \geq 4 \mathrm{~h} / \text { day }\end{array}$ & 254 & 118 & 46.5 & 254 & 84 & 33.1 & $1.76(1.21-2.56$ & 0.002 \\
\hline \multicolumn{9}{|l|}{ Dietary patterns } \\
\hline$>3$ meals/day & 254 & 148 & 58.3 & 254 & 193 & 76.0 & $0.44(0.30-0.66)$ & $<0.001$ \\
\hline Daily breakfast & 254 & 115 & 45.3 & 254 & 148 & 58.3 & $0.59(0.41-0.85)$ & 0.003 \\
\hline \multicolumn{9}{|l|}{ Dietary preferences } \\
\hline Fried foods $>3$ times/week & 254 & 49 & 19.3 & 254 & 51 & 20.1 & $0.95(0.60-1.51)$ & 0.82 \\
\hline Fast food $\geq 3$ times/week & 254 & 45 & 17.7 & 254 & 55 & 21.7 & $0.78(0.49-1.24)$ & 0.26 \\
\hline Sweets $\geq 5$ times/week & 254 & 153 & 60.2 & 254 & 158 & 62.2 & $0.92(0.63-1.34)$ & 0.65 \\
\hline Soft drinks $\geq 5$ times/week & 254 & 115 & 45.3 & 254 & 95 & 37.4 & $1.38(0.96-2.01)$ & 0.07 \\
\hline Fruit $\geq 5$ times/week & 254 & 93 & 36.6 & 254 & 110 & 43.3 & $0.76(0.52-1.10)$ & 0.12 \\
\hline Vegetables $\geq 5$ times/week & 254 & 113 & 44.5 & 254 & 98 & 38.6 & $1.28(0.88-1.85)$ & 0.18 \\
\hline Meat with apparent fat & 254 & 56 & 22.0 & 254 & 46 & 18.1 & $1.28(0.81-2.02)$ & 0.27 \\
\hline \multicolumn{9}{|l|}{ Health habits } \\
\hline Smoking & 254 & 15 & 5.9 & 254 & 12 & 4.7 & $1.27(0.55-2.95)$ & 0.55 \\
\hline Dieting for weight loss & 254 & 71 & 28.0 & 254 & 28 & 11.0 & $3.13(1.89-5.20)$ & $<0.001$ \\
\hline
\end{tabular}

$\mathrm{BMI}$ - body mass index.

${ }^{*} P$-values are taken from the corresponding chi-square tests. Significant $P$-values are indicated in bold type. 
Concerning dietary habits, we noticed that frequency of meals seems to be a protective factor against overweight and obesity. The number of daily meals revealed a significant inverse association with overweight and obesity: subjects who had more than three meals per day were less likely to be overweight and obese than the others. The habit of having breakfast every day was also found to offer protection against overweight and obesity. Concerning the intakes of specific types of food, there were no significant differences between cases and controls.

Cases were three times more likely to report being on a diet for weight-loss purposes (OR 3.13) than controls.

Table 3 shows the results of the multivariate analysis carried out by means of hierarchical conditional logistic regression. Father's and mother's BMI were adjusted for one another. In spite of this adjustment, however, both variables remained strongly associated with overweight and obesity in the adolescent children. Birth weight, when controlled for the variables preceding it in the model (parental nutritional status), lost its effect over obesity and overweight. The same occurred for the variable time watching TV. The adjusted analysis revealed a relative effect (borderline significance) for breast-feeding. Overweight in childhood also maintained its statistical significance. Concerning dietary habits, only the number of meals per day maintained its status as a protective factor against overweight and obesity after adjustment for the four preceding levels of model employed. Of all reported variables, dieting for weight-loss purposes at the time of the interview was the most strongly associated with overweight and obesity in adolescence. Even after adjustment for all preceding variables, it presented an OR of 3.53 .

\section{Discussion}

The relatively short recall period for most information collected contributed to reduce memory bias, and, owing to the small number of losses, selection bias did not seem to have any effect on the results of the study.

This study focused on the higher-level population of the southern region of Brazil due to the greater prevalence of obesity and overweight in adolescents, as revealed by the latest Brazilian survey ${ }^{13}$, among populations of higher socio-economic level in this region.

A possible limitation of this study was the use of weight and height reported by parents. Although the use of reported anthropometric measurements is often criticised, studies of the accuracy of weight reported by the adult population have, in general, confirmed its high correlation with measured weight. For instance, studies carried out in the $\mathrm{USA}^{19}$ and Porto Alegre in southern Brazil ${ }^{20}$ have encountered a high correlation $(r=0.94$ and 0.97 , respectively) between the two values.

Our results show - in agreement with other epidemiological studies ${ }^{1-4}$ - that having parents with high BMI values is a risk factor for overweight and obesity in adolescents. Although family aggregation of obesity certainly has a genetic component, it has also been

Table 3 Hierarchical conditional logistic regression of risk factors for obesity in adolescence: private high schools, Pelotas, southern Brazil, 2000

\begin{tabular}{|c|c|c|c|}
\hline Variable & $\begin{array}{c}\text { Adjusted } \\
\text { OR }(95 \% \mathrm{Cl})\end{array}$ & $P$-value* & Model† \\
\hline \multicolumn{4}{|l|}{ Parental history } \\
\hline Father's BMI $\geq 30 \mathrm{~kg} \mathrm{~m}^{-2}$ & $2.43(1.37-4.30)$ & 0.002 & 1 \\
\hline Mother's $\mathrm{BMI} \geq 30 \mathrm{~kg} \mathrm{~m}^{2}$ & $2.86(1.43-5.74)$ & 0.003 & 1 \\
\hline \multicolumn{4}{|l|}{ Adolescent's history } \\
\hline Birth weight $\geq 3.8 \mathrm{~kg}$ & $1.38(0.76-2.50)$ & 0.29 & 2 \\
\hline Breast-fed $>2$ months & $0.62(0.37-1.03)$ & 0.06 & 3 \\
\hline Self-perception of overweight before age 10 & $2.26(1.30-3.90)$ & 0.004 & 4 \\
\hline \multicolumn{4}{|l|}{ Physical activity (PA) } \\
\hline PA outside school & $0.75(0.44-1.27)$ & 0.31 & 5 \\
\hline Sleep $>8 \mathrm{~h} /$ day & $0.60(0.33-1.08)$ & 0.09 & 5 \\
\hline Watching TV, playing video games and using a computer $\geq 4 \mathrm{~h} /$ day & $1.36(0.77-2.40)$ & 0.29 & 5 \\
\hline \multicolumn{4}{|l|}{ Dietary patterns } \\
\hline$>3$ meals/day & $0.54(0.29-1.00)$ & 0.05 & 5 \\
\hline Daily breakfast & $0.63(0.36-1.10)$ & 0.11 & 5 \\
\hline \multicolumn{4}{|l|}{ Dietary preferences } \\
\hline Soft drinks $\geq 5$ times/week & $1.35(0.77-2.36)$ & 0.29 & 5 \\
\hline Fruit $\geq 5$ times/week & $0.57(0.31-1.05)$ & 0.07 & 5 \\
\hline Vegetables $\geq 5$ times/week & $1.23(0.72-2.10)$ & 0.45 & 5 \\
\hline \multicolumn{4}{|l|}{ Health habits } \\
\hline Dieting for weight loss & $3.53(1.76-7.22)$ & $<0.001$ & 5 \\
\hline
\end{tabular}

OR - odds ratio; $\mathrm{Cl}$ - confidence interval; $\mathrm{BMI}$ - body mass index.

${ }^{*} P$-values are taken from the corresponding chi-square tests. Significant $P$-values are indicated in bold type.

† Model 1 - mother's and father's BMI adjusted for one another; Model 2 - Model 1 plus birth weight; Model 3 - Model 2 plus breast-feeding; Model 4 - Model 3 plus self-perception of overweight before age 10; Model 5 - Model 4 plus physical activity outside school, hours of sleep, hours of TV, video games and computer, number of daily meals, habit of having breakfast, habit of having soft drinks, fruit and vegetables, and dieting for weight-loss purposes at the time of the interview. 
demonstrated that a child or adolescent is at risk of becoming obese simply by living with other obese persons, independent of the existence or not of biological relationships among them ${ }^{21}$.

It has frequently been reported that feeding practices greatly influence children's or adolescents' choices. Family lifestyle and food habits play an important role in the child's or adolescent's food preferences, and this may affect their body weight. Parents are responsible for food availability and accessibility at home. In addition, children's eating habits can be modified through the attitudes of parents, peers, siblings and relatives who live with them. Parents' encouragement to eat promotes fat gain in their children ${ }^{22}$.

In 1997 a retrospective study ${ }^{4}$ evaluated the probability of obesity among young adults, taking into account being overweight or not during several different periods of their lives as well as their parents' nutritional status. These authors also came to the conclusion that children without obese parents were at lower risk of becoming obese adults.

Our hierarchical multivariate analysis allowed risk evaluation for each variable while controlling for possible confounders. This can easily be observed in the 1.5-fold risk associated with birth weight in the crude analysis, which lost its statistical significance after adjustment for parental BMI. In a recent study, Frisancho ${ }^{23}$ also reported this finding: the association between birth weight and body composition during adolescence is mediated by parental body composition. In other words, heavy newborns (assumed to be fat newborns) do not necessarily become fat adolescents unless the mother or father is also overweight.

Childhood overweight as a risk factor was twice as common among cases than among controls. This is consistent with the findings of Serdula et $a l^{3}$ and Power et $a{ }^{1}{ }^{1}$, who performed an extensive bibliography review on the persistence of obesity from childhood to adulthood. All studies showed that obese children are at greater risk of becoming obese adults. The authors found, as well, that the risk of an obese child remaining obese increases with age. According to Whitaker et $a l^{4}{ }^{4}$, relative risk increases considerably if one or both parents are overweight.

The analysis showed a relative protective effect (borderline significance) of total breast-feeding duration on overweight. Many previous studies that have investigated this relationship failed to encounter significant effects $^{10}$, but two recently published articles ${ }^{24,25}$ showed evidence of a protective effect of breast-feeding against obesity later in life. The mechanism by which such protection may occur is uncertain. Some authors ${ }^{25}$ suggest that breast-fed children drink less milk than those on formula, and that the child's dietary preferences are altered by the way in which he/she is fed. In a recent review, Martorell et $a .^{26}$ also suggested that breast-feeding might have a protective effect against future obesity.
The absence of physical activity outside school was not found to be a factor associated with overweight and obesity in adolescents. However, these results have to be interpreted with caution taking into account a possible lack of power to detect some differences. Many studies suggest that sedentary behaviour is common among children and adolescents, and it has been identified as a significant predictor of weight gain in later stages of life. However, long-term longitudinal studies employing accurate techniques for the measurement of physical activity are not available ${ }^{27}$. Physical inactivity has thus been considered to be the most accurate long-term indicator for sedentary behaviour ${ }^{28}$.

Hours of watching TV, playing video games or using a computer per day - indirect indicators of sedentarianism - showed an association with overweight and obesity in crude analysis. In multivariate analysis, after adjustment for the remaining variables, this effect disappeared. The relationship between hours spent watching TV and obesity is controversial; some researchers have encountered a strong relationship ${ }^{29,30}$ whereas others question the existence of a direct relationship ${ }^{31}$.

Dietz and Gortmaker ${ }^{29}$, analysing data from cycles II and III of the National Health Examination Survey, observed that adiposity and amount of time spent in front of the TV during adolescence are significantly associated, even after correction for obesity history. They concluded that TV viewing encourages inactivity as well as the intake of densely caloric foods. It is not clear, however, if the habit of TV viewing amongst children and adolescents actually causes obesity or whether obese children are less physically active due to social stigmatisation from their peers or other secondary factors.

The present study revealed an inverse relationship between meal frequency and body weight, which suggests that the habit of having meals more frequently may be a protective factor against obesity. According to Taylor and Garrow $^{32}$, meal frequency has no major impact on energy intake or expenditure but energy expenditure is delayed with a lower meal frequency compared with a higher meal frequency. This might be attributed to the thermogenic effect of food, continuing into the night when a later, larger meal is given. In a recent review, Bellisle et al. ${ }^{33}$ verified that although many studies fail to find any significant relationship, the relationship is consistently inverse in those studies that do observe one.

The absence of breakfast turned out, in the crude analysis, to be a risk factor for overweight and obesity in the population studied. Other authors have found similar results. While studying the habits of European adolescents, Samuelson ${ }^{34}$ verified that irregularity of meal patterns, characterised mainly by the absence of breakfast, could be related to the increase in the prevalence of obesity observed in Europe during the past decades.

Being on a current diet for weight-loss purposes was the risk factor that presented the highest level of 
association with overweight and obesity. The order of the events in this association, however, cannot properly be elucidated from this study. It is possible that overweight and obese adolescents may be on restrictive diets in order to improve their body image, or simply aiming to adopting a behaviour coherent with their nutritional status. Thus, a possible limitation of this study is reverse causality, a bias frequently observed in casecontrol studies.

In a recent study, Neumark-Sztainer et $a l^{35}$ found that behaviours related to weight control in teenagers were associated with the intake of unhealthy food. Dietary restriction was associated with excessive eating among adolescents. In a study of adolescent girls, Killen et al. ${ }^{36}$ found that restrained eaters exhibited high levels of feelings of worthlessness, body dissatisfaction, fear of weight gain and disaffect, and they were heavier and more physically developed than unrestrained girls.

In conclusion, the present study showed that a family history of obesity, overweight during childhood and the habit of dieting for weight-loss purposes are risk factors for obesity during adolescence. The habit of having more than three daily meals turned out to be a protective factor against overweight. These results suggest that obesity control policies and programmes should be as precocious as possible, being directed not only at adolescents, but also at their families and the community in general. These activities should be developed by both health and education professionals, acting directly at their institutions as well as by advertising in mass media such as newspapers, magazines, radio and TV, and electronic media. In this context, school plays an important role in the improvement of food and physical activity habits.

\section{References}

1 Power C, Lake JK, Cole TJ. Measurement and long-term health risks of child and adolescent fatness. International Journal of Obesity and Related Metabolic Disorders 1997; 21 : 507-26.

2 Power C, Lake JK, Cole TJ. Body mass index and height from childhood to adulthood in the 1958 British birth cohort. American Journal of Clinical Nutrition 1997; 66: 1094-101.

3 Serdula MK, Ivery D, Coates RJ, Freedman DS, Williamson DF, Byers T. Do obese children become obese adults? A review of the literature. Preventive Medicine 1993; 22: $167-77$.

4 Whitaker RC, Wright JA, Pepe MS, Seidel KD, Dietz WH. Predicting obesity in young adulthood from childhood and parental obesity. New England Journal of Medicine 1997; 337: 869-73.

5 Gortmaker SL, Must A, Perrin JM, Sobol AM, Dietz WH. Social and economic consequences of overweight in adolescence and young adulthood. New England Journal of Medicine 1993; 329(14): 1008-12.

6 Di Pietro L, Mossberg HO, Stunkard A. A 40-year history of overweight children in Stockholm: life-time overweight, morbidity, and mortality. International Journal of Obesity 1994; 18: 585-90.
7 Must A, Jaques PF, Dallal GE, Bajema CJ, Dietz WH. Long term morbidity and mortality of overweight adolescents: a follow-up of the Harvard Growth Study of 1922 to 1935. New England Journal of Medicine 1992; 327(19): $1350-5$.

8 Wasbitsch M. Overweight and obesity in European children and adolescents: causes and consequences, treatment and prevention. An introduction. European Journal of Pediatrics 2000; 159(Suppl.): S5-7.

9 Troiano RP, Flegal KM. Overweight children and adolescents: description, epidemiology and demographics. Pediatrics 1998; 101(3): 497-504.

10 Parsons TJ, Power C, Logan S, Summerbell CD. Childhood predictors of adult obesity: a systematic review. International Journal of Obesity 1999; 23(Suppl. 8): S1-107.

11 Drewnowski A, Popkin BM. The nutrition transition: new trends in the global diet. Nutrition Reviews 1997; 55(2): $31-43$.

12 Peña $\mathrm{M}$, Bacallao J. La obesidad en la pobreza: un problema emergente en las Américas. In: Organización Panamericana de la Salud (OPS)/Organización Mundial de la Salud (OMS), ed. La Obesidad en la Probreza: Un Nuevo Reto para la Salud Pública. Washington, DC/Geneva: OPS/OMS, 2000; $3-11$.

13 Neutzling MB, Taddei JAAC, Rodrigues EM, Sigulem DM. Overweight and obesity in Brazilian adolescents. International Journal of Obesity 2000; 24: 1-7.

14 Duarte MFS. Maturação física: uma revisão da literatura, com especial atenção à criança brasileira. Cadernos de Saúde Püblica 1993; 9(Suppl. 1): 71-84.

15 Rutter M. Pesquisa de Mercado. São Paulo: Ática; 1988.

16 Kirkwood BR. Essentials of Medical Statistics. London: Blackwell Scientific, 1988.

17 Victora CG, Huttly SR, Fuchs SC, Olinto MTA. The role of conceptual frameworks in epidemiological analysis: a hierarchical approach. International Journal of Epidemio$\log y$ 1997; 26: 224-7.

18 Mickey RM, Greenland S. The impact of confounder selection criteria on effect estimation. American Journal of Epidemiology 1989; 131: 652-63.

19 Reed DR, Price RA. Estimates of the heights and weights of family members: accuracy of informant reports. International Journal of Obesity 1998; 22: 827-35.

20 Schmidt M, Duncan B, Tavares M, Polanczyk C, Pellanda L, Zimmer P. Validity of self-reported weight - a study of urban Brazilian adults. Revista de Saúde Pública 1993; 27: 271-6.

21 Stunkard AJ. Factores determinantes de la obesidad: opinión actual. In: Organización Panamericana de la Salud (OPS)/Organización Mundial de la Salud (OMS), ed. La Obesidad en la Pobreza: Un Nuevo Reto para la Salud Pública. Washington, DC/Geneva: OPS/OMS, 2000; 27-32.

22 Maffeis C. Aetiology of overweight and obesity in children and adolescents. European Journal of Pediatrics 2000; 159(Suppl.): S35-44.

23 Frisancho R. Prenatal compared with parental origins of adolescent fatness. American Journal of Clinical Nutrition 2000; 72: 1186-90.

24 Von Kries R, Koletzko B, Sauerwald T, von Mutius E, Barnert $\mathrm{D}$, Grunert V, et al. Breastfeeding and obesity: cross sectional study. British Medical Journal 1999; 319: 147-50.

25 Gillman MW, Rifas-Shiman SL, Camargo CA Jr, Berkey CS, Fraizier AL, Rockett HRH, et al. Risk of overweight among adolescents who were breastfed as infants. Journal of the American Medical Association 2001; 285: 2461-7.

26 Martorell R, Stein AD, Schroeder DG. Early nutrition and later adiposity. Journal of Nutrition 2001; 131(3): 874S-80S.

27 Livingstone B. Epidemiology of childhood obesity in Europe. European Journal of Pediatrics 2000; 159(Suppl.): S14-34. 
28 Kohl HW, Hobbs KE. Development of physical activity behaviors among children and adolescents. Pediatrics 1998; 101: 549-54.

29 Dietz WH, Gortmaker SL. Do we fatten our children at the television set? Obesity and television viewing in children and adolescents. Pediatrics 1985; 75: 807-12.

30 Gortmaker SL, Must A, Sobol AM, Peterson K, Colditz GA, Dietz WH. Television viewing as a cause of increasing obesity among children in the United States, 1986-1990. Archives of Pediatrics \& Adolescent Medicine 1996; 150(4): 356-62.

31 Robinson TN, Hammer LD, Killen JD, Kraemer HC, Wilson DM, Hayward C, et al. Does television viewing increase obesity and reduce physical activity? Cross sectional and longitudinal analyses among adolescent girls. Pediatrics 1993; 91: 273-80.

32 Taylor MA, Garrow JS. Compared with nibbling, neither gorging nor a morning fast affect short-term energy balance in obese patients in a chamber calorimeter. International
Journal of Obesity and Related Metabolic Disorders 2001; 25(4): 519-28.

33 Bellisle F, McDevitt R, Prentice AM. Meal frequency and energy balance. British Journal of Nutrition 1997; 77(1): $57-70$.

34 Samuelson G. Dietary habits and nutritional status in adolescents over Europe. An overview of current studies in the Nordic countries. European Journal of Clinical Nutrition 2000; 54(Suppl. 1): S21-8.

35 Neumark-Sztainer D, Rock CL, Thornquist MD, Cheskin LJ, Neuhouser ML, Barnett MJ. Weight-control behaviors among adults and adolescents: associations with dietary intake. Preventive Medicine 2000; 30: 381-91.

36 Killen JD, Taylor CB, Hayward C, Wilson DM, Haydel KF, Hammer LD, et al. Pursuit of thinness and onset of eating disorder symptoms in a community sample of adolescent girls: a three-year prospective analysis. International Journal of Eating Disorders 1994; 16(3): $227-38$. 